\title{
ASSESSMENT OF HEALTH SEEKING BEHAVIOR REGARDING COMPLEMENTARY AND ALTERNATIVE MEDICINE IN SOLUKHUMBU DISTRICT, NEPAL
}

\author{
Kafle PP, Pant PP, Dhakal N
}

Department of Community Medicine, Nepal Medical College Teaching Hospital, Attarkhel, Gokarneshwor-8,

\begin{abstract}
The objective of the study was to assess the health seeking behavior of the people regarding complementary and alternative medicine (CAM) in remote area Dhudhakaushika, Gaunpalika of Solukumbu District during April - August 2017. The sample size was 300 (129 male and 171 female). Semi-structured question was design and Focus Group Discussion (FGD) was conducted. The results indicated that about three fourths of the respondents visited a modern medical institution 224 (74.7\%), a little under one-half 129 (43.0\%) visited Dhami-Jhakri and 85 (28.3\%) contacted the Jharphuke who chanted a Mantra over a sick adult or child. Around 33 (11.0\%) contacted the female community health volunteer (FCHV), $20(6.7 \%)$ used domestic medicine or ethno- medicine, $13(4.3 \%)$ visited a pharmacy and 9(3.0\%) visited a private allopathic clinic when they felt discomfort. Respondents ascribed the cause of the disease to supernatural causes or evil spirits (53.3\%), to germs $(48.7 \%)$, curse of God (83.0\%) to sins committed in the past (10.3\%), and other causes (5.7\%). The respondents usually consulted at first Dhami-Jhakri (43.0\%) and Jharphuke $(28.3 \%)$ when they fell sick. People utilized CAM in order to relieve undesired pain, uneasiness in the body and restore the health condition. The types of alternative medicine utilized by the respondents were Ayurveda 162 (54.0\%), jadi-booti 248 (82.7\%), homeopathy 94 (31.3\%), relaxation $33(11.0 \%)$, and meditation $68(22.7 \%)$ healing touch $55(18.3 \%)$, therapeutic massage 109 (36.3\%), acupuncture 126 (42.0\%), acupressure $44(14.7 \%)$ Yoga $28(3.3 \%)$ and 10 (3.3\%) did not know any practice other than Dhamijhakri. Through the FGD, it was observed that traditional medicine sector was an important source of health care in Solukhumbu. The main reasons for consulting a CAM healer were the proximity, affordable barter system, availability, family pressure and the strong opinion of the community. In conclusion, CAM use especially self-treatment with medicinal plants was found to be a common practice along with modern medicine in a rural setting in Nepal. The study findings emphasized the reality of multiple recourse adopted by health care seekers and their deeply entrenched belief in CAM. Nepal has a very rich tradition in the use of medicinal plants for the treatment of various ailments. This may indicate the need for the integration of the modern and CAM systems in terms of evidence-based information sharing. This calls for bringing CAM healers into the mainstream by providing them with proper training, facilities and referral services. The healers can motivate the persons to access modern health care services by placing a Tika of ash (Kharani) prior to referral. A positive interaction between the two systems has to be harnessed to work for the common goal of improving health of the people.
\end{abstract}

\section{KEYWORDS}

Curse of God, evil spirits, Dhamijhakri, Jharphuke, Jadibooti, Nepal

\section{CORRESPONDING AUTHOR}

Dr. Phanindra Prasad Kafle

Department of Community Medicine,

Nepal Medical College Teaching Hospital,

Attarkhel, Gokarneshwor-8, Kathmandu, Nepal

Email: kaflephanindra@nmcth.edu

Orcid No: https://orcid.org/0000-0001-7245-2469

DOI: https://www.doi.org/10.3126/nmcj.v23i1.36223 


\section{INTRODUCTION}

Complementary and alternative medicine (CAM) comprises of a group of varying medical and health systems, practices and products that are not typically considered as conventional medicine. Despite advances in allopathic medicine, a substantial proportion of the global population continue to utilize CAM. ${ }^{1}$ Moreover, CAM has gained popularity worldwide over the last decade and acknowledged with the establishment of the US National Center for CAM. $^{2}$

According to data from population-based studies in high income countries such as Australia, UK, Taiwan, Singapore, and the United States of America, about one-half to twothirds of adults have used CAM. ${ }^{3}$ Traditional systems of medicine have continued to play an important role in improving and maintaining health in low and middle income countries. ${ }^{4}$ The World Health Organization (WHO) has defined 'traditional medicine as diverse health practices, approaches, knowledge and beliefs incorporating plant, animal, and/or mineral based medicine, spiritual therapies, manual techniques and exercises applied singularly or in combination to maintain well-being, as well as to treat, diagnose or prevent illness' ${ }^{5}$ Due to the pluralistic nature of health care systems, a person's treatment-seeking behavior can be characterized by the use of multiple treatment modalities either sequentially or simultaneously. ${ }^{6,7}$ Studies on treatment-seeking behavior typically look at the individual's first treatment choice. ${ }^{8}$ In order to fully understand the importance of traditional medicine, we should not confine our analyses to first recourse treatments, but include multiple recourses. This will help to reveal the true utilization pattern of traditional medicine. ${ }^{9}$

While a diverse system of traditional medicine is prevalent in Asia, very few studies have quantified the reliance of the native populations on traditional medicine. Research has been confined to illness-specific studies and on whether households have ever used traditional medicine. ${ }^{10,11}$ The practice of selftreatment with or without the use of traditional medicine has been overlooked or excluded from studies. ${ }^{12}$ Moreover, many studies that have quantified the use of 'informal' treatment practices have not paid specific attention to the various traditional systems of medicine and instead grouped any treatment other than visits to allopathic treatment facilities into the same treatment category (e.g., traditional healer treatments are grouped together with pharmacy visits). ${ }^{13}$
Consequently, the pattern and determinants of traditional medicine utilization have rarely been studied in Asia. We do not know 'how many people are reliant on traditional medicine and what factors determine this reliance'? In Nepal, several medical systems are utilized by the population, but not all of these are recognized by the government. Allopathic medicine has been prioritized by the government since its inclusion into Nepalese health care policy in the $1950 \mathrm{~s} .{ }^{14}$ Ayurveda was formally recognized and a policy of Ayurveda was formulated in 1996. ${ }^{15}$

Solukhumbu is a remote district in the landlocked country of Nepal in South Asia. It consists of the subregions Solu and Khumbu. The district covers an area of $3,312 \mathrm{~km}^{2}$ and had a population of a little over 1 lac in 2011 . The main attraction in this district is Mount Everest and the UNESCO listed World Heritage site the Sagarmatha National Park.

It has a multi ethnic composition with Sherpa, Magar, Tamang and other. Indigenous ethnic Rai and hill caste Chhetri are the main people groups living in the mid-hills, while Sherpas occupy high mountains. (CBS census 2011).

Nepal is ranked $145^{\text {th }}$ out of 187 countries on the Human Development Index and had in 2012 a total population of 31 million of which $17.3 \%$ lived in urban areas. ${ }^{16}$ Life expectancy is 68.8 years. ${ }^{17}$ Public health services are provided through a system of 3129 sub-health posts, 676 health posts, 209 primary health care centers and 65 district hospitals. Additionally, there are zonal/regional/central level hospitals providing specialized care. Public Ayurvedic health services are also provided through 214 Ayurveda dispensaries, 61 district Ayurveda health centers, and a total of 16 zonal/central level Ayurveda hospitals. ${ }^{18}$ Nepal also has a large private health sector, receiving about half of all outpatient visits for acute illnesses. ${ }^{19}$ Health care delivery is a challenge in the hilly and mountainous parts of the country due to the lack of infrastructure. ${ }^{20}$

Data from LMICs on knowledge and perception of medical practices towards CAM is limited. The objective of this study was to assess the knowledge, attitude and usage of CAM among people living in a remote area of Nepal.

The general objective of this study was to assess the health seeking behavior of the people on CAM. The specific objectives were to assess the knowledge and attitude and practice regarding CAM, study the health seeking behavior regarding CAM in different perspectives 
and factors which influence health seeking behavior in remote area.

\section{MATERIALS AND METHODS}

Mixed methodology was used in this descriptive study. A semi structured questionnaire was designed in local language 'Nepali' and translated into English for analysis. The pre-tested questionnaire gathered the information from respondents on demographic data, knowledge, attitude and usage of complementary and alternative medicine. A pilot study of the questionnaire was conducted within the group to determine the face validity of the questionnaire and correct ambiguities. The survey was carried out among 300 respondents. Among them 20 persons were selected for focus group discussion (FGD) and conducted in two groups 10 person in each group. During FGD two cases were selected for in-depth case study. Each interview time was 20 minutes and 45 minutes for each FGD after taking verbal consent. The duration of study was between March - August 2017.

Research area and study population: Dhudhakaushika Gaupalika of Solukhumbu district. Study population was health seeking persons above 20 years who participated in a health camp. Systematic random sampling method was applied. Each alternate person that attended the health camp and met the inclusion the criteria was invited to participate in the study. Assuming the prevalence of CAM use at $50 \%$ with an allowable error of $6 \%$ the sample size was calculated to be 240 respondents. A $15 \%$ non- response rate was estimated with the final sample size being 300 respondents. All of the respondents had one or more health complaints. Trained local enumerators along with researcher collected the data through semi structured pre tested questionnaire. Prior approval for this study was obtained from the Institutional Research Committee (IRC) of Nepal Medical College.

Study variable determination and measurements: knowledge, attitude and usage were measured using both closed and openended questions. Due to the subjectivity of selfreported levels of perception, a more objective procedure was used to assess the health seeking pattern of the respondents who claimed to be either receiver or provider of CAM. Data analysis was done using Statistical Package for the Social Sciences (SPSS16). Descriptive statistical tools such as frequencies, percentages and proportions were used to report the data.

\section{RESULTS}

Total numbers of the respondents were three hundred. Among them 129(43\%) were male and $171(57 \%)$ were female. The minimum age was 20 years and maximum age was 80 years. Seventy -eight(26\%) were 30-39 years old, 64(21.3\%) were $40-49$ years old, 59(19.7\%) were 50-59 years old, 49(16.3\%) of the respondents were aged between 20-29 years, 42(14.0\%) were 6069 years and 70 and above were $8(2.7 \%)$.

Table 1: Occupation of the respondents

\begin{tabular}{|lcc|} 
Occupation & $\mathbf{n}$ & $\mathbf{\%}$ \\
\hline Home maker & 57 & 19 \\
Agriculture & 184 & 61.3 \\
Service & 34 & 11.3 \\
Labour & 2 & 0.7 \\
Business & 10 & 3.3 \\
Others & 13 & 4.3 \\
Total & $\mathbf{3 0 0}$ & $\mathbf{1 0 0 . 0}$ \\
\hline
\end{tabular}

Table 1. A majority of the respondents were involved in agricultural work (61.3\%), 19\% were homemakers, $11.3 \%$ were in service, 3.3\% were engaged in business and a small minority were labourers $(0.7 \%)$. The other $13(4.3 \%)$ were CAM practitioners such as Dhami-Jhakri, Jharphuke, Baidhe, priest, Herbal practice, Yoga therapy, touch healing etc.

\begin{tabular}{|lcc|}
\hline \multicolumn{3}{|c|}{ Table 2: Education status } \\
\hline Level of education & $\mathbf{n}$ & $\mathbf{\%}$ \\
\hline No education (Illiterate) & 129 & 43 \\
Primary education & 104 & 34.7 \\
Secondary level & 30 & 10 \\
Certificate level & 12 & 4 \\
Bachelor level & 15 & 5 \\
Master degree and above & 10 & 3.3 \\
\hline Total & $\mathbf{3 0 0}$ & $\mathbf{1 0 0}$ \\
\hline
\end{tabular}

Table 2 depicted the educational status of the respondents. Out of 300,129(43\%) respondents were illiterate, 104(34.7\%) were literate with a primarylevel of education, $30(10 \%)$ respondents had a secondary (SLC) level education, 12(4.0\%) respondents had a certification, 15(5\%) respondents had a bachelor level degree and 10 (3.3\%) respondents had a master's degree and above. 


\begin{tabular}{|lcc|}
\hline \multicolumn{3}{|c}{ Table 3: Economic status of the } \\
respondents
\end{tabular}

Majority of the respondents 180(60\%) had an annual income of less than NRs. 25,000. The earning of the $78(26 \%)$ was Rs. 25,000 to Rs. 40,000 . Twenty (6.7\%) were earning Rs. 41000 to Rs. $1,00,000$. Six (2\%) of the respondents were earning Rs. $1,10,000$ to Rs. 1,50,000. The respondent whose earning was above Rs. $1,50,000$ was $14(4.7 \%)$. Two (0.7\%) respondents did not have any countable income.

About 188 (62.7\%) of the respondents lived in a nuclear family, 107(35.7\%) respondents were living in a joint family and $5(1.7 \%)$ were in extended families. The respondents were predominantly Hindu by religion 289(96.3\%), Buddhist 8(2.7\%), and only 3(1\%) were Christian.

\begin{tabular}{|lcc|}
\multicolumn{3}{|c|}{$\begin{array}{c}\text { Table 4: Respondents' beliefs regarding } \\
\text { cause of diseases or sickness }\end{array}$} \\
\hline Type & $\mathbf{n}$ & $\mathbf{\%}$ \\
\hline Curse of God & 25 & 8.3 \\
Past sins & 31 & 10.3 \\
Due to devils (evil eye) & 160 & 53.3 \\
Germs & 146 & 48.7 \\
Others (habit and genetic) & 17 & 5.7 \\
\hline
\end{tabular}

Table 4 . The most commonly ascribed cause of disease was believed to be the evil eye (53.3\%) and germs (48.7\%), past sins (10.3\%), Curse of God (8.3\%), habits and genetic factors (5.7\%).

Table 5. About three fourths of the respondents visited a medical institution 224 (74.7\%). A little under one-half 129 (43.0\%) visited Dhami-Jhakri, when they felt sick and 85 (28.3\%) contacted the Jharphuke who chanted a Mantra over a sick adult or child. Around 33 (11.0\%) contacted the female community health volunteer (FCHV), $20(6.7 \%)$ used domestic medicine or ethnomedicine, $13(4.3 \%)$ visited a pharmacy and 9 (3.0\%) visited a private allopathic clinic when they felt discomfort.

Table 5: Respondents multiple recourse during sickness of any member in the family

\begin{tabular}{|lcc|} 
Type & $\mathbf{n}$ & $\mathbf{\%}$ \\
\hline Dhami-Jhakri & 129 & 43.0 \\
Jharphuke & 85 & 28.3 \\
Medical institution & 224 & 74.7 \\
FCHV & 33 & 11.0 \\
Private clinic & 9 & 3.0 \\
Domestic medicine & 20 & 6.7 \\
Pharmacy & 13 & 4.3 \\
\hline
\end{tabular}

\begin{tabular}{|lcc|}
\hline \multicolumn{3}{|c|}{$\begin{array}{c}\text { Table 6: CAM awareness among } \\
\text { respondents }\end{array}$} \\
\hline Type & n & \% \\
\hline Ayurveda & 162 & 54 \\
Herbs (Jadibooti) & 248 & 82.7 \\
Homeopathy & 94 & 31.3 \\
Relaxation therapy & 33 & 11 \\
Meditation & 68 & 22.7 \\
Healing touch & 55 & 18.3 \\
Therapeutic message & 109 & 36.3 \\
Acupuncture & 136 & 42 \\
Acupressure & 44 & 14.7 \\
Yoga & 28 & 9.3 \\
Others & 10 & 3.3 \\
\hline
\end{tabular}

Among the respondents, 162 (54.0\%) knew about Ayurveda, herbs 248 (82.7\%), homeopathy 94 (31.3\%), relaxation $33(11.0 \%)$, meditation 68 (22.7\%), healing touch 55 (18.3), therapeutic massage 109 (36.3\%), acupuncture $126(42.0 \%)$, acupressure $44(14.7 \%)$, yoga 28 (9.3\%). The other 10 (3.3\%) alternate medicine included laughing therapy, singing, counting different numbers and sacrificing the animals and birds to the supernatural being.

\begin{tabular}{|lcc|}
\multicolumn{3}{|c|}{ Table 7: Payment modalities to CAM } \\
practitioners
\end{tabular}

Commodities (alcohol/goods/poultry) were offered by 252 (84.0\%), money 152 (50.7\%) and substitute work $22(7.3 \%)$ were also used to pay CAM practitioners. 
FGD results: Most of the respondents were familiar with CAM. They believed that 'unhappy devils like Bhut-pret, Pishach, Dankani, Bayu used in witchcraft disturb the health of a person. Those unhappy devils need to be made happy by providing different goods and sometimes sacrificing the animal or birds also'. They believed that Dhamijhakri, Baidang, and Jotish (astrologers) were able to perform rituals and win the sentiment or favor of these supernatural forces.

Role of Dhamijhakri and Baidang: Usually the CAM practitioners invite the 'unhappy spirits' by using different Mantra and separate special place (Than) and tools (brass plate, raw rice, Chamber (tail of yak), Kucho (broom), ash, different flowers and Bheti (Paisa), eggs, Raxi (local wine) to make them happy and requested them to go away and and not return or disturb the persons again. Then the CAM practitioners would give some herbal medicine (Jadibootiroots, ash, flower, plants, blood of sacrificed animal/or birds, non-sacred goat, pigeon, duck and cock) rice etc. to eat or wear on the body.

About a half of the FGD participants were comfortable with treatment from traditional healers like Dhami-Jhakri however some respondents did not believe in Dhami-Jhakri. Persons who preferred to contact Jharphuke (healers that chant Mantras to relieve discomfort in a sick adult or child) also believed in allopathic medicine. They said that they would visit a health institution if a Jharphuke would advise them to do so. If the healer was not able to treat a severe case, they would be putting a blessing (Tika) and send the person to a modern health setting,

The respondents said that they prepared medicine at home when they fell sick. They believed that they could trust the medicine that was prepared from local available materials which acts in a safe and gradual manner. According to many respondents the allopathic medicines only help to suppress the disease but did not cure. The respondents expressed concerns about the adverse effects of modern medicine.

Through the FGD, it was observed that traditional medicine sector was an important source of health care in Solukhumbu. The main reasons for consulting a CAM healer were the proximity, affordable barter system, availability, family pressure and the strong opinion of the community. They recommended the CAM might be included in the educational curriculums. CAM service was based on a mutual understanding, easy, affordable, approachable and available at a low cost. The health seeking person did not know the exact problems but when they consulted the CAM provider, they received instruction on the ways of treatment.

\section{DISCUSSION}

The study findings emphasized the reality of multiple recourse adopted by health care seekers and their deeply entrenched belief in CAM. Not surprisingly, in this remote corner of Nepal, the majority of the respondents cultivated crops while about one-fifth were homemakers. In a rural place, household work involves a significant time being spent on collecting grass and firewood, cooking, preparing cultural materials and maintaining rapport with the community at large. While a few (11.3\%) were involved in civil service, teaching, cooperative banking, and security army /police, a small number were employed as labourers. The respondents who were local business persons would collect the local products for sale and provide imported goods to local consumers. About $4.0 \%$ were involved in practicing alternative medicine such as Dhami-Jhakri, Jharphuke, Baidhe, priest, Herbal practice, Yoga therapy, touch healing. Pokhrel and Sauerborn ${ }^{8}$ have found that the first treatment seeking behaviour is influenced by personal as well as family choice in many developing countries. A person's occupation and level of knowledge was an important determinant that guided the adoption of learned behavior. ${ }^{8}$

Clement et $a l^{23}$ have reported that educational status can influence decision making and health seeking behaviour, however this was not entirely reflected in this study. Despite a low level of literacy (43.0\% illiterate and 34.7\% primary level), three-fourths of the respondents had opted to seek modern medical care. During the FGDs, it was revealed that though modern medicine was sought, CAM was a common modality of treatment that was also favoured by those with a higher education.

The economic status of the respondents was assessed to know the impact of income in health practice and belief in CAM and modern medicine. An overwhelming number of respondents $(86.0 \%)$ were found to be below poverty line (who could not earn 1.25\$ US Dollar per day). The World Bank report in 2014 mentioned that in Nepal about $57.3 \%$ of the people were below poverty line (earning less than 2 dollar per day). ${ }^{22}$ In this study, a small proportion (14.0\%) of respondents were above the poverty line (Table 3 ). The FGDs revealed 
that CAM users were often persons who were employers of the CAM practitioners and a barter system of payment was mutually beneficial. Interestingly, persons living in nuclear families preferred CAM rather than those from joint and extended families.

Despite the remote location of the study population, their health seeking behavior in terms of first recourse to treatment was modern (about $75.0 \%$ of the respondents visited health institution when sick). However, CAM continued to be a popular treatment recourse among the respondents. The National Institute of Health (2002) had mentioned that the assimilation of CAM has increased dramatically worldwide over the past several years. Regarding awareness of different CAM systems, multiple responses were obtained from respondents. The more commonly knowns CAM were DhamiJhakri and Jadibooti (Herbal). The prevalent socio-cultural beliefs were found to influence the utilization of CAM as revealed during the FGD. Studies have shown that knowledge on CAM modalities differ among countries. In Singapore and Pakistan, acupuncture is the best known CAM, American students consider massage, herbal medicine and meditation as their best known CAMs. ${ }^{13}$

The common assumption among researchers and policy makers regarding the use of traditional medicine is that poor and marginalized people are most reliant on traditional medicine due to its availability. This study has shown that socio-cultural beliefs can influence persons with higher education and knowledge of medicinal plants regarding the use of traditional medicine.

These findings support the current traditional medicine policy's focus on expanding the coverage of traditional medicine facilities in Nepal. Nepal has a very rich tradition in the use of medicinal plants for the treatment of various ailments. The importance of self-treatment with medicinal plants, despite the availability of allopathic medicine has highlighted the people's preference for home-based traditional treatments as first recourses. Traditional knowledge of medicinal plants has been studied in ethnobotanic and ethnoecological research. ${ }^{24}$ In order to ensure that self-treatment with medicinal plants will remain an option in the future, there is a need for building human capital and knowledge base.

CAM provides diverse options for people during their treatment-seeking strategy. Recognizing the diverse relationships of people to traditional medicine and medicinal plants (Jadibooti) is important to support the needs of local people and to enable institutions to adapt to changing treatment-seeking patterns. Understanding the determinants of traditional medicine use in LMICs and relationships between household income and traditional medicine use would be useful. It is crucial to understand if rising income in developing countries will lead to an increase in traditional medicine use as has been observed in developed countries.

In Africa, it is estimated that one traditional healer takes care of the health needs of about 500 people especially in rural areas and up to $80.0 \%$ of the population use traditional medicine for their primary health care needs. ${ }^{25}$ In recognizing the role played by these traditional healers, WHO is encouraging countries to promote and integrate traditional medical practices in their health care systems. ${ }^{22}$

The fact that $80.0 \%$ of Africans are known to use traditional medicine confirms the assumption that having a family member using a CAM modality, among other factors such as the environment, personal interest, religious beliefs, and cultural background influence a person's knowledge and attitude towards the use of CAM. ${ }^{25}$

A study in the United States of America in 2007 reported that almost 4 out of 10 adults had used some form of CAM within the previous year. ${ }^{26}$ This increasing patronage of CAM is driven by its perceived success in recovering, healing, improving health, and more importantly, perceived lack of side effects, lower cost, and prompt attention compared to conventional medicines and practice..$^{29}$

Through the quantitative and qualitative assessment, it was observed that traditional medicine was an important source of health care in Solukhumbu. The main reasons for consulting a CAM healer were the proximity, affordable barter system, availability, family pressure and the strong opinion of the community. This may indicate the need for the integration of the modern and CAM systems in terms of evidence-based information sharing. The health-seeking behavior of the people in developing countries calls for bringing CAM healers into the mainstream by providing them with proper training, facilities and referral services. The healers can motivate the persons to access modern health care services by placing a Tika of ash (Kharani) prior to referral. A positive interaction between the two systems has to be harnessed to work for the common goal of improving health of the people. 
Studies across medical schools in different countries reveal that most medical undergraduate students were receptive to the introduction of CAM in the curriculum. ${ }^{28}$ The knowledge and usage of CAM among medical students in USA was probably better due to the integration of CAM into their medical curriculum. ${ }^{29}$ However, in a study among medical students in China, only $33.1 \%$ were favourable towards the inclusion of CAM in the curriculum.
In conclusion, complementary and alternative medicine use especially self-treatment with medicinal plants was found to be a common practice along with modern medicine in a rural setting in Nepal. This study does not advocate CAM; however, this research aims to improve our understanding of treatment-seeking behaviour. The findings may offer an updated base-line information for the researchers in this field and help inform the development of better targeted health interventions and policies.

\section{REFERENCES}

1. Barnes PM, Powell-Griner E, McFann K, Nahin RL. Complementary and alternative medicine use among adults: United States, 2002. Adv Data 2004; 343: 1-19.

2. National Center for Complementary and Integrative Health, 2005. Complementary and Alternative Medicine in the United States.Online available on https://www.ncbi.nlm.nih.gov/ books/NBK83804/ (Accessed on: January 8 2020)

3. Ceylan S, Azal O, Taslipinar A, Turker T, Acikel CN and Gulec M. Complementary and Alternative Medicine Use Among Turkish Diabetes Patients. Complementary Therapies Med 2008; 17: 78-83.

4. Cunningham AB, Shanley P, Laird S. 2008. Health, habitats and medicinal plant use. In: Colfer CJ, editor. (ed). Human health and forests: A global overview of issues, practice and policy. People and Plants International Conservation Series. London: Earthscan, pp. 35-62.

5. WHO, 2012. Traditional and Complementary Medicine Policy. Geneva: WHO. https://apps. who.int/iris/rest/bitstreams/434690/retrieve, (Accessed November 21 2020)

6. Weller SC, Ruebush TR, Klein RE. Predicting treatment-seeking behavior in Guatemala: a comparison of the health services research and decision-theoretic approaches. Med Anthropol Quarterly 1997; 11: 224-45. [PubMed]

7. Ryan GW. What do sequential behavioral patterns suggest about the medical decisionmaking process?: Modelling home case management of acute illnesses in a rural Cameroonian village. Social Sci Med 1998; 46: 209-25. [PubMed]

8. Pokhrel S, Sauerborn R. Household decisionmaking on child health care in developing countries: the case of Nepal. Health Policy Planning 2004; 19: 218-33. [PubMed]

9. Sato A. Revealing the popularity of traditional medicine in light of multiple recourses and outcome measurements from a user's perspective in Ghana. Health Policy Planning 2012; 27: 625-37. [PubMed]

10. Chaturvedi HK, Mahanta J, Pandey A. Treatmentseeking for febrile illness in north-east India: and epidemiological study for the malaria endemic zone. Malaria J 2009; 8: 301. [PubMed]

11. Sydara K, Gneunphonsavath S, Wahlström $\mathrm{R}$, et al. Use of traditional medicine in Lao PDR. Complementary Therapies Med 2005; 13: 199-205.[PubMed]

12. Mayxay M, Hansana V, Sengphilom B, et al. Respiratory illness healthcare-seeking behavior assessment in the Lao People's Democratic Republic (Laos). BMC Public Health 2013; 13: 444. [PubMed]

13. Chenge MF, Vennet JVD, Loboya NO, et al. Healthseeking behaviour in the city of Lubumbashi, Democratic Republic of the Congo: results from a cross-sectional household survey. BMC Health Serv Res 2014; 14: 173. [PubMed]

14. Cameron M. Modern desires, knowledge control, and physician resistance: regulating Ayurvedic medicine in Nepal. Asian Med 2008; 4: 86-112.

15. Department of Ayurveda. 1996. The National Ayurveda Health Policy 2052 (1996). Kathmandu: Ministry of Health.

16. UNDP. Human Development Report 2013 - The rise of the South: Human progress in a diverse world. New York: United Nations Development Programme.

17. UNDP. Nepal Human Development Report 2014 Beyond geography, unlocking human potential. Kathmandu: Government of Nepal, National Planning Commission and United Nations Development Programme, Nepal.

18. Department of Health Services. 2012. Annual Report 2067/68 (2010/2011). Kathmandu: Ministry of Health and Population.

19. WHO. 2007. Health System in Nepal: Challenges and Strategic Options. Kathmandu: World Health Organization, Country office for Nepal.

20. Bentley $H$. The organization of Health Care in Nepal. Int'l J Nurs Studies 1995; 32: 26070. [PubMed]

21. Ben-Arye E, Frenkel M, Klein A, Scharf M. Attitudes toward integration of complementary and alternative medicine in primary care: perspectives of patients, physicians and 
complementary practitioner. Patient Educ Couns, 70 (suppl 3) (2008), pp. 395-402

22. Chenge MF, Vennet JVD, Loboya NO, et al. Healthseeking behaviour in the city of Lubumbashi, Democratic Republic of the Congo: results from a cross-sectional household survey. $B M C$ Health Serv Res 2014; 14: 173. [PMC free article] [PubMed]

23. Clement YN, Williams AF, Khan A, et al. A gap between acceptance and knowledge of herbal remedies by physicians: the need for educational interventions. BMC Complement Altern Med, 5 (2005), p. 20

24. WHO. WHO Traditional Medicine Strategy 2014 - 2023. World Health Organization (2013).

25. Truter I. African traditional healers: cultural and religious beliefs intertwined in a holistic way. SA Pharm J 2007; 74: 56-60.

26. Al-Faris EA, Al-Rowais N, Mohamed AG, et al. Prevalence and pattern of alternative medicine use: the results of a household survey. Ann Saudi Med 2008; 28: 4-10.

27. Lee GBW, Charn TC, Chew ZH, Ng TP. Complementary and alternative medicine use in patients with chronic diseases in primary care is associated with perceived quality of care and cultural beliefs. Fam Pract 2004; 21: 654-60.

28. Lie DA, Boker J. Comparative survey of complementary and alternative medicine (CAM) attitudes, use, and information-seeking behaviour among medical students, residents \& faculty. BMC Med Edu 2006; 9: 58.

29. National Center for Complementary and Alternative Medicine. Traditional Chinese medicine: what you need to know. http://nccam. nih.gov/health/whatiscam/chinesemed.htm. Assessed on 7th December, 2020. 